\title{
Omnichannel Marketing on Integrated Retail Store in Indonesia
}

\author{
Stephanny Lianardo \\ Institut Komunikasi dan Bisnis LSPR, Jakarta, Indonesia
}

\begin{abstract}
Omnichannel marketing should focus on creating an immersive environment in order to create a seamless experience for the customers. In this research, we are looking into the omnichannel marketing applied by PT. Erafone DotCom to integrate their fairly new online platform with their existing physical store and the public perspective toward it. We find out that despite the public being familiar with their physical store, the public is still largely unaware and unfamiliar with the existence of eraspace.com as the online platform of Erafone thus rendering the omnichannel marketing to be less effective. We also look into the public perspective of the idea of omnichannel marketing that has been applied by PT. Erafone DotCom and analyze how to improve the public awareness about eraspace.com and what strategy to improve the omnichannel marketing that has been applied in order to create an immersive environment for the customers to have seamless experience in shopping with Erafone and/or eraspace.com.
\end{abstract}

Keywords: Omnichannel marketing; integrated retail store; customer experience; seamless experience

\section{INTRODUCTION}

Rapid development of communication technology has contributed on people's behaviour, including their buying behaviour. Indonesia is also included in this phenomenon whereas cited on DataReportal (Kemp \& Moey, 2019) that 90\% of Indonesian internet users between the ages of 16 and 64 reporting that they already buy products and services online. This trend of online shopping behaviour has been a threat for the offline side of the retail business. This issue has also been communicated by Satria Hamid, Vice President Corporate Communication Trans Retail Indonesia in an interview with CNN Indonesia on 2019 "The offline retail competition has grown tougher, moreover with the influence from the online retail market. Thus, innovative strategy is needed for surviving in the industry." In response to the threat from the online market, the offline businesses of Trans Retail Indonesia, such as Carrefour and Transmart have adopted new innovations, such as 'tour in one facility' where people able to shop for their groceries as well as experience shopping in a department store, eat, and also kids' playground in the form of mini theme park all at the same time.

The example given by Satria Hamid has been focusing of tactile experience of the customer. Meanwhile, with online shopping experience, customers are practically detached from this tactile experience as they only shops through the screen of their computers or smartphones. The ability to see, touch and feel products as well as take items home immediately rank highest among the reason consumers choose to shop in stores versus online. (Skrovan, 2017). 
Customers also utilize several channels whether through physical channel or all the other digital channels available within the internet network to search and make even a single purchase. Omnichannel management refers to the integration of all these channels of a firm and customer touchpoints, which ultimately results in customer satisfaction through a seamless service experience. (Hossain et al., 2019)

While often mistaken with Multichannel Marketing, Omnichannel Marketing differs from it in multiple dimensions, which are company strategy and consumer behavior. The noticeable differences within those dimensions are how same information and messages go through across the available channels in uniform manner, the degree of unified database regarding customer and inventory, the consumer purchase journey design, and the amount of effort needed by customer to move across the channel. (Berman \& Thelen, 2018).

Aside from that, E-commerce is the essential part in Omnichannel Retail. As the subjects of this research is an E-commerce retailer which is residing in Indonesia, it is important to look into the environment of the industry. As mentioned before, $90 \%$ of Indonesian internet users within the productive range have experiencing online shopping in a way or another. DataReportal (Kemp \& Moey, 2019) also reported that Electronics \& Physical Media category, which PT. Erafone DotCom falls under, has been the second highest in terms of total annual amount of consumer e-commerce spending with USD 2.643 billion per January 2019 with 24\% of positive growth.

This phenomenon raises the question for effective marketing strategy to balance the advantage from both the traditional channels and the online channels of retail businesses. One of the retail companies that is facing this challenge is PT. Erafone DotCom. As stated on their company website, PT. Erafone DotCom is a subsidiary company of PT. Erajaya Swasembada Tbk., which is an Indonesian online retail company revolve around electronics and communication technology such as smartphones and the accessories. In order to maximize the effectiveness of their marketing channels, they recently apply the omnichannel system in collaboration with PT. Erafone Artha Retailindo, another subsidiary of PT. Erajaya Swasembada Tbk., that handling the offline smartphone retail side of the business.

This situation rises the questions that motivates this research topic regarding the challenges and issues the company faces in the application of the channel strategy; the countermeasures that they have taken and how effective it is; and also, public opinion about this and how this influences their buying decision. There has been past research done on Omnichannel Marketing in retail industry in which focuses on how Omnichannel impacts the facility provided by physical store to optimize its service (Gao et al., 2018). As comparison, this research will focus more on the customer experience as Omnichannel Marketing is still fairly new in Indonesia.

\section{METHOD}

The main method used in conducting this research is survey that will be conducted through online questionnaire. The survey is needed to know what is the public perspective in regards to the omnichannel strategy that is implemented by the company. 
An online survey has been conducted through Google Forms with 54 respondents in total. The questionnaire contains 15 questions including basic questions like gender, age and city of domicile of the respondents. The questionnaire targets the respondents that live in Java Island as the omnichannel marketing of PT. Erafone DotCom only applies in Java Island area as of now.

\section{RESULT AND ANALYSIS}

PT. Erafone DotCom is an Indonesian e-commerce company that is a subsidiary from PT. Erajaya Swasembada Tbk. Its main company, PT. Erafone Swasembada Tbk., is a retailer company in Indonesia with the main focus on electronic appliances, especially communication technology appliances, such as mobile phones, smartphones, laptops, and also their attachments or accessories. Aside from selling the products, they also handle the official store and service centres on many well-known brands, such as Apples (iBox), Samsung, Huawai, Xiaomi, and many mores.

PT. Erafone DotCom handles the e-commerce sides of the main company, which mainly focus on selling mobile phones or smartphones at first under the web address https://erafone.com but has since moves to another address. The new address is https://eraspace.com/ as the main company has expand their business area on the products such as lifestyle and home electronic appliances, laptops, and now beauty products.

PT. Erafone DotCom begin their omnichannel marketing starting from the second quarter of year 2018. The omnichannel marketing comes in the form of pick-up options in the physical store for the customer that order from their online platform. The aim of this is to ensure the customer to feel save in purchasing through online platform as there are a lot of scam practice in buying electronics, including smartphone, through online. With the customer experience in mind, they believe that once the customers feel satisfied experiencing shopping through them then the profit would come along with it.

The majority of respondents which are 43 out of 54 respondents come from the age of 21-30 years old and the rest 11 respondents come from 31-40 years old age group. As of the gender, the majority of respondents which are 35 out of 54 respondents come from male gender group and the rest 19 participants come from female gender group.

As for the city of domicile, the majority of respondents which is 23 out of 54 respondents reside in Jakarta, the capital city of Indonesia, while the rest comes from various cities across Java Island, such as Bandung, Bekasi, Tangerang, Surabaya, Yogyakarta, Bogor, Depok, Pekalongan, Semarang, and Blitar.

Table 1. Domicile of Respondents

\begin{tabular}{|l|c|}
\hline \multicolumn{1}{|c|}{ City } & Number of Respondents \\
\hline Jakarta & 23 \\
\hline Bandung & 7 \\
\hline Bekasi & 7 \\
\hline Tangerang & 5 \\
\hline Surabaya & 3 \\
\hline
\end{tabular}




\begin{tabular}{|l|c|}
\hline Yogyakarta & 2 \\
\hline Bogor & 2 \\
\hline Depok & 2 \\
\hline Pekalongan & 1 \\
\hline Semarang & 1 \\
\hline Blitar & 1 \\
\hline \multicolumn{2}{|c|}{ Source: Data processed by Author (2020) } \\
\hline
\end{tabular}

As the main area of business of PT. Erafone DotCom and what they are known the best is mobile phone and smartphone, thus knowing their buying behaviour specifically related to those products is important to understand better how their overall opinion on the omnichannel retail. The majority of respondents which is 37 out of 54 respondents buy a new mobile phone or smartphone once every two to three years. As the number respondents who answered they buy new phone once every four to five years is 20 out of 54 respondents. While there are 3 out of 54 respondents answered that they buy a new phone once a year and once more than five years. The offline platform which entails physical store, is the preferred choice of 36 respondents. Only 18 out of 54 respondents prefer the online platform which includes eraspace.com and other major e-commerce available in Indonesia.

Based on the result of the questionnaire, majority of respondents which is $83.3 \%$ answered that they are familiar with Erafone. Although, the other way is true about their awareness and familiarity about eraspace.com as the e-commerce platform by Erafone. There are only 13 out of 54 respondents answered that they are familiar with eraspace.com. There are even less people that is aware of the omnichannel feature offered on the website, which is only $7.4 \%$ of the respondents.

There are some questions in the survey asking about some aspects of the one omnichannel feature offered by Erafone, which is the pick-up point from physical store option with possibility to have product replacement in case a defect has been found. There are vast majority of the respondents responded positively in regards to the question of whether this option would increase their comfort and positive shopping experience as a customer, with $78 \%$ of respondents answered highly agree and $13 \%$ agree with the statement. Only a small portion answered disagree (2\%) and highly disagree (7\%).

As how much this option picks their interest to buying through eraspace.com, there are no one in the respondents answered that they are highly disagree. Again, a vast majority answered positively with $72 \%$ of the respondents agree that this option attracts their interest in buying through eraspace.com and $11 \%$ of the respondents answered highly agree. The rest of the respondents (17\%) answered that they disagree with the statement.

In regards of sense of security, only a small portion of respondents (2\%) disagree that the option increases the sense of security in experiencing shopping at eraspace.com. Most of the respondents (31\%) agree with the statement of increase in sense of security and more than half of total respondents (67\%) highly agree with the statement. In relations to sense of security is the credibility of Erafone and/or eraspace.com. Similar with the previous statement, majority of the respondents answered positively with how the option would increase the credibility of Erafone and eraspace.com as a store, with $22 \%$ of respondents answered highly agree and $70 \%$ answered agree to the statement. The rest of $8 \%$ of the respondents answered disagree. 
As for practicality in buying experience, there are $52 \%$ of respondents that are agree and $28 \%$ of respondents answering highly agree. There are only $15 \%$ of respondents disagree and $5 \%$ highly disagree with the option would increase the practicality in buying experience.

Aside from the closed questions listed above, there are a couple of open questions to understand the opinion of the respondents even more. The first open question was specified to the respondents that answered disagree or highly disagree in one or more previous questions. In this question, they were asked to explain their reasoning of their negative answers to the statement related to the omnichannel option offered by eraspace.com.

Hereby are the more important and noticeable answers since some of them answers similarly or answers of similar nature. The first one is the most noticeable answer, which describe how the respondents know so little about eraspace.com thus they cannot readily agree to some of the statements in the survey. The next noticeable answer is that they feel like the concept of bridging both online and offline platform in the form of omnichannel seems complicated for them to understand and gain benefit from using the omnichannel feature. This answer is closely related to another answer where the respondents stated that they still prefer to strictly buy mobile phone or smartphone strictly through offline or physical store as it is more comfortable to them.

Aside for those who answered that they are more comfortable with strictly buying electronic products through physical stores, there are also those who answered that they prefer that if they shop through online platform, they want the experience to be detached from the physical store. Their reasoning is that it takes more effort to go and pick up the items at the physical store thus defeats the reason why they shop through online platform as the first place. While they agree that the fact, they will be able to have product replacement in case of finding a defect in the product they buy would increase the sense of security in their shopping experience, they feel like it is more important in the first place that the seller, in this case Erafone or eraspace.com, ensure the quality of the product before sending it off to the buyer.

Interestingly, there is also a respondent that answered they feel like a business should be built on the trust from the business to the customers and vice versa. The respondent also mentioned that the pick up at physical stores only focus on the things concerning the business instead the customers, thus it feels like there is no trust as the foundation of it.

The second open question on this survey is asking about the opinions of the respondents on what other features they feel they want to see applied by Erafone or eraspace.com in the future for their omnichannel marketing to improve customers' shopping experience. This question gives insight on some possible countermeasures of some issues that arises from previous open question. Below are the answers from the respondents.

The most suggested comment is to increase the number of the physical store pick up points. A couple of respondents has answered that the closest physical stores available to them are quite faraway, thus it would be a lot of effort made into buying from Erafone or eraspace.com. While there is also a respondent answered that it would be helpful if the information of the closest physical stores available for pickup service is available prior to processing the online order. Another one also added suggestion for information of physical stores operating hour for 
pickup service to be available on the website. Along with the first suggestion, there is also a suggestion to increase the coverage to include big cities outside Java Island, like in Sumatera or Kalimantan Island, so more customers can enjoy the omnichannel option as well.

Second is the suggestion for development of Cash-on-delivery (COD) scheme. An addition that can be made on this scheme is wide range of payment options. While cash on delivery usually refers to payment method using hard cash, it is not necessarily limited to only hard cash. The courier personnel can be equipped with wireless electronic data capture terminal so the customers will be able to pay using either debit card or credit card upon receiving their order. This practice has been applied by restaurant delivery service such as Pizza Hut Delivery and McDonald's. This is to cater for older customer that might not be as technology savvy as customer from younger generation but still desire the practicality that comes with it.

Along with the wireless electronic data capture terminal, the courier can also be equipped with a specified smartphone to process payment transaction via digital wallet, especially for the target users that come from the younger generation. The usage of digital wallet has been rising in the past few years as reported on The Jakarta Post (2019) with 74.6\% of digital wallet apps users in Indonesia come from 20 to 35 years old age group. Also reported on the same article is the top five digital wallet apps in Indonesia per second quartal of 2019, which are GoPay, OVO, DANA, LinkAja, and Jenius. So far, eraspace.com only covers two method of digital wallets which are GoPay and OVO. The two payment methods through digital wallet only apply for the payment transaction done on the website for now and have not yet applied as payment option for the cash on delivery service. As digital wallet apps only need one device, which is a smartphone, it is easier to set up and to be brought around by the courier personnel. Once the item has been checked and received by the buyer, then the buyer can just input their phone number or scan the QR code on the device from the courier personnel to complete the payment transaction.

\section{CONCLUSION}

Omnichannel marketing should focus on creating an immersive environment in order to create a seamless experience for the customers. PT. Erafone DotCom as a subsidiary company or PT. Erajaya Swasembada Tbk., handles the online platform counterpart of the existing offline retail store from their main company. PT. Erafone DotCom has recently started in trying to bridge the gap between their online platform with the offline platform which is the physical stores handled by the main company. The form of omnichannel marketing that has been featured by PT. Erafone DotCom is the pick up at physical stores option being offered to the customers that make purchase through their online platform, which is eraspace.com. Unfortunately, PT. Erafone DotCom has yet to achieve in creating an immersive environment for the customers to have a seamless experience.

The reason why PT. Erafone DotCom has not been successful in creating the seamless experience is reflected by the result of the survey conducted during the research for this thesis. The public awareness and familiarity about eraspace.com as the online platform of the brand Erafone, the physical retail store handled by PT. Erajaya Swasembada Tbk., as the main company, is still very low. Although, the majority of the respondents respond positively with the omnichannel features that has been applied by PT. Erafone DotCom. 
In conclusion, PT. Erafone DotCom needs to work on raising the awareness of the public about eraspace.com as the online platform of Erafone retail store first, before working on the omnichannel marketing in order to achieve immersive environment for a seamless shopping experience. In order for them to raise the awareness and familiarity of the public, PT. Erafone DotCom need to make a promotional campaign and advertisement to properly introduce eraspace.com to the public. They also need to create account handle on top social network service platforms such as Facebook, Twitter, and Instagram. Additionally, it is a good idea to work together with social media influencers and content creators to create a social media content for promoting eraspace.com to the public.

After raising the awareness, PT. Erafone DotCom then can start to improve their omnichannel marketing by adding features that improve interactivity between their online and offline platform in order to create an immersive environment and seamless shopping experience. Firstly, they need to strengthen their foundation, in this case their website, by adding a community gathering feature to encourage active involvement from the users who are also their potential customers. Another addition that is needed in order to strengthen the foundation is to have mobile application that is synchronized in function with eraspace.com website to improve the accessibility and also online activity of the website users. They also need to keep the flow of information on their internal management information system to be as real-time, accurate, and accessible as possible to improve on their existing omnichannel marketing features so they become more effective and efficient.

Secondly, PT. Erafone DotCom need to focus on bridging the online platform with the physical store with features that cater not only to the customers from the online platform to enjoy the tactile experience that can only be obtained through physical offline platform, but also they need to cater the customers from the physical store and pull them to use and enjoy the benefit of the online platform as well. Some example of features that can be installed in the physical store to create an immersive environment for the customer to enjoy the benefit from both platform are installing a display with a QR code for the customer to synchronize their login account to the system in the physical store; synchronization of purchase history, promotional code, perks and rewards with the data in the online login account and the purchase made at the physical store; real-time accessibility to online reviews of the products they interested in by scanning the QR code provided on the product information display in the physical store; and also mini games provided for customers waiting in line for their turns with additional perks or reward points that are able to be obtained for their online login account.

Additionally, PT. Erafone DotCom can also apply more technologically advanced features to differentiate themselves further from the competitors. The features are augmented reality technology and virtual reality technology. Augmented reality technology will be able to increase the immersive environment and seamless experience for the customer when applied. As for the virtual reality technology, aside from creating more seamless experience for the customers, it also functions as a test product of what they sell.

There are some limitations in this research. First and foremost, the suggestions resulted from the analysis of the survey form still need to be researched separately to estimate the effectiveness of each suggestion. A cost analysis is also needed to calculate before applying the suggestion and also to plan out the timing for applying and introducing the features to the 
customers. The suggestions might also work differently in terms of effectiveness depending on the location of stores where the suggestions will be applied in.

The suggestions made from the analysis also based on the normal situation where the physical store is still operating normally. As with the Covid-19 outbreak that affects the business operational, Erafone physical stores have been closed for a few months with no information for approximate time of when the physical stores can start to operate again. Thus, separate research to assess the economy and business situation during the pandemic is needed. There also a need for separate research on how omnichannel marketing can be applied with social and physical distancing practice in mind in preparation for the 'new normal' era.

\section{REFERENCES}

Becker, M. (2016). The Differences Between Multichannel \& Omnichannel Marketing. EMARSYS. https://emarsys.com/learn/blog/multi-channel-marketing-omnichannel/

Berman, B. \& Thelen, S. (2018). Planning and implementing an effective omnichannel marketing program. International Journal of Retail \& Distribution Management, 46(7), 598-614. https://doi.org/10.1108/IJRDM-08-2016-0131

Erajaya (2020). Company Profile. Erajaya. from https://www.erajaya.com/company-profile

Erajaya (2020). Subsidiaries \& Affiliates. https://www.erajaya.com/subsidiary-companies

Fauzie, Y.Y. (2019, June 25). Meneropong Masa Depan Ritel di Tengah Badai Gulung Tikar. CNN Indonesia. https://www.cnnindonesia.com/ekonomi/20190625115907-92406174/meneropong-masa-depan-ritel-di-tengah-badai-gulung-tikar

Gao, F., Agrawal, V., \& Cui, S. (2018). The Effect of Multi-Channel and Omni-Channel Retailing on Physical Stores. Forthcoming in Management Science. https://dx.doi.org/10.2139/ssrn.3212274

Harris, E. (2012, May 17). A Look At Omni-Channel Retailing. Retail It Insights. https://www.retailitinsights.com/doc/a-look-at-omni-channel-retailing-ooo1

Hossain, T. M. T., Akter, S., Kattiyapornpong, U., \& Dwivedi, Y. (2020). Reconceptualizing Integration Quality Dynamics for Omnichannel Marketing. Industrial Marketing Management, 87, 225-241. https://doi.org/10.1016/j.indmarman.2019.12.006

Johnston, R. and Kong, X. (2011). The customer experience: a road-map for improvement. Managing Service Quality, 21(1), 5-24. http://dx.doi.org/10.1108/09604521111100225

Kemp, S., \& Moey, S. (2019, September 18). Digital 2019 Spotlight: Ecommerce in Indonesia. DataReportal. https://datareportal.com/reports/digital-2019-ecommerce-inindonesia 
Müller, J. (2020, February 19). Penetration of leading social networks in Indonesia as of 3rd quarter 2019. Statista. https://www.statista.com/statistics/284437/indonesia-socialnetwork-penetration/

Skrovan, S. (2017, February 22). Why most shoppers still choose brick-and-mortar stores over e-commerce. Retail Dive. https://www.retaildive.com/news/why-most-shoppersstill-choose-brick-and-mortar-stores-over-e-commerce/436068/

THE JAKARTA POST (2019, August 14). The top five e-wallet apps in Indonesia. The Jakarta Post. https://www.thejakartapost.com/life/2019/o8/14/the-top-five-e-wallet-appsin-indonesia.html 